\title{
Exploring mentorship as a strategy to build capacity for knowledge translation research and practice: a scoping systematic review
}

\author{
Anna R Gagliardi ${ }^{*}$, Fiona Webster ${ }^{2}$, Laure Perrier ${ }^{3}$, Mary Bell ${ }^{4}$ and Sharon Straus ${ }^{3}$
}

\begin{abstract}
Background: Knowledge translation (KT) supports use of evidence in healthcare decision making but is not widely practiced. Mentoring is a promising means of developing $\mathrm{KT}$ capacity. The purpose of this scoping systematic review was to identify essential components of mentoring that could be adapted for KT mentorship.

Methods: Key social sciences and management databases were searched from January 2002 to December 2011 inclusive. Empirical research in non-healthcare settings that examined mentorship design and impact for improving job-specific knowledge and skill were eligible. Members of the study team independently selected eligible studies, and extracted and summarized data.

Results: Of 2,101 search results, 293 were retrieved and 13 studies were eligible for review. All but one reported improvements in knowledge, skill, or behavior. Mentoring program components included combining preliminary workshop-based training with individual mentoring provided either in person or remotely; training of mentors; and periodic mentoring for at least an hour over a minimum period of six months. Barriers included the need for infrastructure for recruitment, matching, and training; lack of clarity in mentoring goals; and limited satisfaction with mentors and their availability. Findings were analyzed against a conceptual framework of factors that influence mentoring design and impact to identify issues warranting further research.

Conclusion: This study identified key mentoring components that could be adapted for KT mentorship. Overall, few studies were identified. Thus further research should explore whether and how mentoring should be tailored to baseline knowledge or skill and individual KT needs; evaluate newly developed or existing KT mentorship programs based on the factors identified here; and examine whether and how KT mentorship develops KT capacity. The conceptual framework could be used to develop or evaluate KT mentoring programs.
\end{abstract}

Keywords: Knowledge translation, Mentorship

\section{Background}

\section{Knowledge translation}

Despite widespread focus on quality in the healthcare sector, performance reports highlight the need to improve the organization, delivery, and outcomes of healthcare services and programs [1]. Knowledge translation (KT) refers to an approach for improving healthcare and its outcomes by promoting and supporting the use of research in clinical, management, and policy-level decision-making [2]. KT includes knowledge transfer

\footnotetext{
*Correspondence: anna.gagliardi@uhnresearch.ca

'University Health Network, Toronto, Canada

Full list of author information is available at the end of the article
}

or dissemination, which refer to unidirectional sharing of research through mechanisms such as publications or presentations. KT also includes knowledge exchange, which refers to multidirectional interaction among researchers and decision makers for the conduct of research, program planning, evaluation, or quality improvement [3]. KT is a complex, multi-step, cyclical process that involves synthesizing evidence and creating knowledge products; interacting with target users to assess needs and identify barriers; using that information to tailor evidence syntheses or knowledge products and select implementation strategies; applying implementation strategies; and monitoring to evaluate impact and ensure that research use is sustained 
[2]. KT is a practice that can be applied by those interested in implementing newly generated evidence, or improving healthcare and its outcomes by promoting use of existing evidence. $\mathrm{KT}$ is also an evolving science that builds on theory and approaches from other disciplines to generate evidence on factors that influence research use, or on approaches, strategies and interventions that effectively support research use [4].

\section{KT capacity}

KT capacity is needed to better equip those interested or engaged in KT practice or science. Decision makers, including clinicians, managers and policy makers, have professed that they are unfamiliar with, or confused about the concept and practice of KT, which may be why KT is not widely practiced [5,6]. In Canada, a survey of 240 health services researchers, and another survey of 265 directors of research organizations found that the majority shared research findings by disseminating them in print or electronic form $[7,8]$. Research in Australia and the United Kingdom identified the need to foster $\mathrm{KT}$ practice and research in nursing and primary care [9-12]. KT research was prioritized among practitioners and teachers of emergency medicine from 16 countries [13]. They acknowledged that few emergency medicine investigators have the skills to undertake KT research, and underscored the need to form linkages between emergency medicine clinician investigators and $\mathrm{KT}$ scientists to foster and support the conduct of KT research [14-16]. Interviews with individuals from 33 research funding agencies in Australia, Canada, France, the Netherlands, Scandinavia, the United Kingdom, and United States revealed a widespread need to increase our understanding and practice of KT [17]. We interviewed 18 researchers, clinicians, managers and policy makers who described many KT challenges including lack of awareness of what KT is and how to achieve it, little infrastructure for $\mathrm{KT}$, and the absence of incentives to plan for and engage in KT [18].

Clearly, both researchers and decision makers require knowledge and skill to engage in KT practice or science. Recognizing this need, the United States National Institutes of Health and Veterans Health Administration developed a five-day training institute for postdoctoral fellows to learn about dissemination and implementation [19]. It was intended to function as a train-the-trainer program where participants share their learnings with others at their home institutions. The program included large group discussion and interactive small group sessions. Evaluation of the inaugural program by its 35 participants revealed that most had shared information with colleagues and submitted new grant applications. To improve the program participants recommended additional content on research design and research team leadership, and one-on-one mentorship to reinforce learning. Mentorship was a component of the Implementation Research Institute offered at Washington University in the United States [20] and the KT Canada Strategic Training Initiative [21].

\section{Mentorship}

Mentorship is an interactive, facilitative process meant to promote learning and development that is based on educational and social learning theories [22]. Mentoring has been studied within the context of large corporations where it is used for training, professional development, and succession planning [23]. Seminal research by Kram found that mentoring consists of support for both professional (sponsorship, exposure and visibility, coaching, protection, challenging) and psychosocial (role modeling, acceptance and confirmation, counseling, friendship) development, and typically proceeds through four stages: initiation, cultivation, separation, and redefinition [24]. Significant benefits are associated with mentorship. Mentees receive more promotions, have higher salaries, experience less stress and conflict, are more satisfied with their jobs and careers, and are less likely to leave their organizations compared with non-mentees $[25,26]$. These positive outcomes are associated with both formal (matches made by a third party) and informal (self-initiated) mentorship, and are sustained longitudinally compared with those not mentored [26-28]. Mentors also derive benefit from mentoring including satisfaction from helping others, creation of free time for alternate pursuits, organizational recognition or reward, and improved job performance through exposure to new ideas $[29,30]$.

\section{Mentorship in healthcare}

In healthcare, mentoring has largely been studied in the context of academic medicine where physician trainees or junior physician investigators are mentored by those more experienced for career and personal development [31]. The benefits of academic medicine mentorship include greater grant capture, peer-reviewed publications, faster academic promotion, and higher career satisfaction [32]. A systematic review of published research on academic mentoring described the attributes and actions of an academic mentor, and several personal, relational, and structural barriers of mentoring [33]. Interviews with mentor and mentee physicians revealed that, while most believed academic mentorship to be important, they experienced difficulty in establishing productive mentoring relationships [34]. Strategies to enhance mentorship suggested by interview participants included the development of formal mentorship initiatives, and mentorship training for mentors and mentees. Mentoring has also been used for academic mentorship of student and novice nurses [35-39]. A large proportion of nurses reported having one or more mentors who served a variety of formal and informal roles [40]. A systematic review of academic mentoring 
in nursing found that it was associated with greater job satisfaction and academic achievement [41]. Interviews with, and surveys of mentor and mentee nurses emphasized the need for greater clarity of objectives, and strategies to identify and train mentors [42-44]. Mentoring was also recognized within the nursing literature as an important mechanism for research training in both university and clinical settings though the details of mentoring program design were not described $[45,46]$.

\section{KT mentorship}

Research funders, educators, investigators, and decision makers worldwide have identified the need to improve the quality of healthcare by building capacity for $\mathrm{KT}$. Training programs for KT practice and science are few. Mentorship is a strategy that enhances access to knowledge which could be used alone, or in conjunction with KT training programs to develop KT capacity. However, limited empirical research has examined its application in healthcare, particularly outside of academic mentorship for physicians or nurses. Mentorship has been widely used in disciplines other than healthcare. The purpose of this research was to review literature in management and social sciences and identify essential components of mentoring programs that could be adapted for KT mentorship. More specifically, this review described the quantity and quality of research employing a variety of designs on mentorship, and examined the effectiveness of mentorship when used to develop job-related knowledge and skills among professionals in non-healthcare settings.

\section{Methods}

\section{Approach}

We conducted a scoping review of published research in the social sciences and management disciplines [47]. While similar in rigor to a traditional systematic review, a scoping review addresses broader, more complex topics where different study designs may be relevant and selection criteria are developed post hoc based on increasing familiarity with the literature [47]. A scoping review examines the way strategies, in this case mentorship, are used and their effectiveness, but also describes the nature of the literature to identify whether sufficient evidence exists to support a full systematic review. A scoping review also identifies gaps in the literature that can only be addressed through ongoing research. Preferred Reporting Items for Systematic Reviews and Meta-Analyses (PRISMA) criteria guided reporting of the methods and findings [48]. A protocol for this review was not registered.

\section{Conceptual framework}

There is no single theory or model that describes mentorship processes, outcomes, and influencing factors. However, a useful framework for this study was developed by Karcher, who reviewed educational and psychology literature to outline elements of mentoring program design that might influence outcomes (goals, format, delivery, content, barriers) [22]. These elements, plus barriers of mentoring identified in our background review of research (identifying/ securing mentors, scheduling, clarity of goals, negotiating process, preferences, training, stage-specific evaluation, incentives), and additional mentoring features identified by others were integrated with the Karcher framework [23-30]. The components of the conceptual framework (Figure 1) were used to interpret themes that emerged from the data. Unique themes were added to the conceptual framework.

\section{Data collection}

Business Source Premier (BSP) and Social Sciences Citation Index (SSCI) were searched from January 2002 to December 2011 inclusive for empirical studies focusing on mentorship features and outcomes (Table 1). These represent key databases featuring the largest volume of published research in those disciplines. This date range reflected the most recent ten years of published research at the time of this review. Search strategies were purposefully broad to avoid eliminating potentially relevant items. They were developed by an information scientist with input from the study team. Search terms included mentor or coach as truncated terms to capture words stemming from these. The references of all eligible studies were also screened for relevancy. Mentorship was defined as any interactive process involving one or more mentors and mentees to promote professional development and/or improved professional performance related to specific knowledge or skills. Preliminary selection criteria included quantitative (surveys, observational studies, randomized trials), qualitative (interviews, focus groups) and mixed methods studies published in English language that focused on evaluating mentorship programs for the outcomes of knowledge and skills and provided sufficient detail to extract study design and findings. As search results were reviewed, selection criteria were expanded to specify studies that were not eligible. These included studies that focused on sport coaching or coach training, the development of psychosocial skills among mentees, or mentor characteristics, or were published in management or social sciences journals but studied mentorship in healthcare settings. Studies in the form of abstracts, letters, commentaries, or editorials were not eligible. Systematic reviews, though eligible in general, were excluded because they were conceptual or theoretical, focused on psychosocial benefits, characteristics of mentors or mentees, or did not evaluate mentorship program design. Titles and abstracts of search results were reviewed independently by two investigators and a research assistant. Titles and abstracts were re-screened by the principal investigator and a research assistant with refined eligibility criteria. Rather than calibrating agreement on initial 


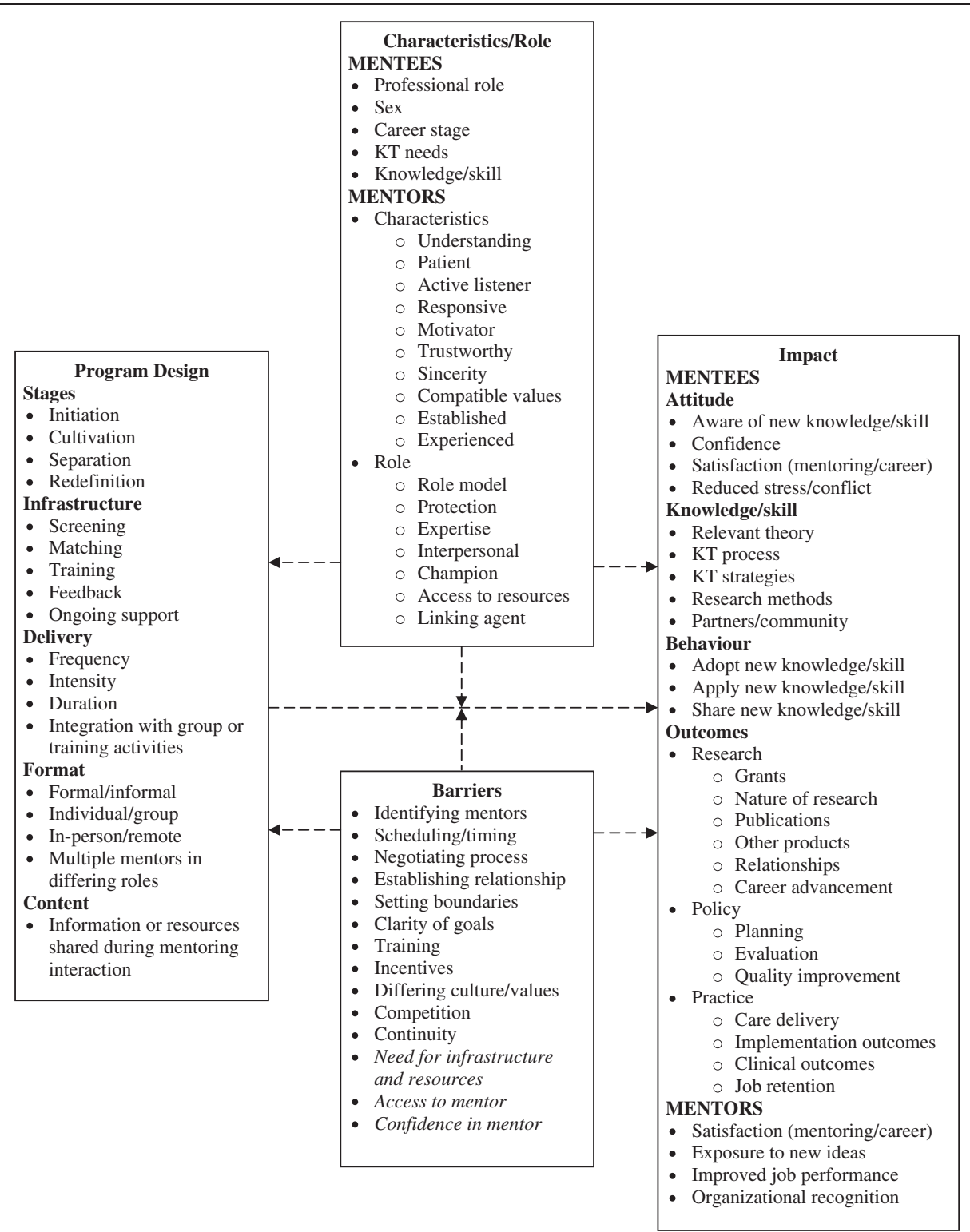

Figure 1 Conceptual framework of factors influencing KT mentorship design and impact. Italicized text represents elements not originally included in the framework that emerged from eligible studies

selections, all items selected by at least one reviewer were retrieved for further assessment since judgment about eligibility must often be reserved until the full text can be reviewed. If more than one publication described a single study and each presented the same data, the most recent was included.

\section{Data extraction, analysis, and synthesis}

A data extraction form was developed based on the conceptual framework to describe mentoring program goals, impact and design. The form was pilot tested independently by ARG and a research assistant for ten randomly selected articles. Extracted data were then compared to determine whether and how the form should be revised. Data were independently extracted by two research assistants from all articles using the updated form. Study quality was assessed using criteria relevant to study design, but was not used to exclude studies. This included the Cochrane Risk of Bias tool for randomized controlled trials, and a modified version of the Downs and Black instrument for observational studies $[49,50]$. Search results were depicted with a PRISMA flow diagram [48]. Extracted data were tabulated and the quantity, design, quality, and setting of studies were summarized. Studies included a wide range of designs, measures, and outcomes so pooling of data was 
Table 1 Search strategies

\begin{tabular}{ll}
\hline Source & Search terms used* \\
\hline Business Source Premiere & (mentor* OR coach*) NOT ((youth OR adolescen* OR teen* OR sport* OR athlet* \\
& OR football OR "high school*" OR basketball* OR golf*) OR Source (IEEE Transactions)). \\
& The following limits, available when searches were executed, were applied: Scholarly \\
& (Peer Reviewed) Journals; Publication Type: Academic Journal; Document Type: Article; \\
& Search modes - Boolean/Phrase \\
& Note: IEEE Transactions includes several publications issued by the Institute of Electrical \\
& and Electronics Engineers on electrical engineering, computing, biotechnology, telecommunications, \\
& power and energy which generated a high number of ineligible articles and were therefore excluded \\
& (mentor* OR coach*) NOT (youth OR adolescent* OR teen* OR sport* OR athlet* OR football* \\
Social Sciences Citation Index & OR "high schoo**" OR basketball* OR golf*) AND Language = (English) AND Document Types = (Article) \\
\end{tabular}

not possible. Tabulated data were examined for trends or possible links between mentoring program design and outcomes to identify models that may be suitable for KT mentorship. Gaps in knowledge were also identified to issue recommendations for ongoing research.

\section{Results}

\section{Study characteristics}

The initial search resulted in 2,101 articles, of which 297 were retrieved as potentially relevant and further assessed. Of these, 13 studies (nine management, four social sciences) were eligible for review (Figure 2). Data are summarized in Table 2 [51-63]. At least one eligible article was published in eight of the ten years searched (other than 2006 and 2007) with a high of five published in 2009. More than half of the studies (seven) were conducted in the United States. Others were conducted in the United Kingdom (four), China (one), and Puerto
Rico (one). Studies from management literature took place in manufacturing, tourism, educational institutions, financial services, service related industries, and non-profit settings. Studies from social sciences literature were predominantly based in educational environments including elementary and middle schools, and professional education programs.

Quality assessment results appear in Table 2. The single randomized controlled trial had a low risk of bias. The 12 observational studies (eight mixed method program evaluations, four surveys) scored between 7 to 11 (median 9) on a scale of 11 with a higher score indicating higher study quality.

\section{Mentoring goals and impact}

Studies examined impact of mentorship on self-reported overall job performance [51-58], and objectively assessed business performance [59], teaching skills [60-62], and

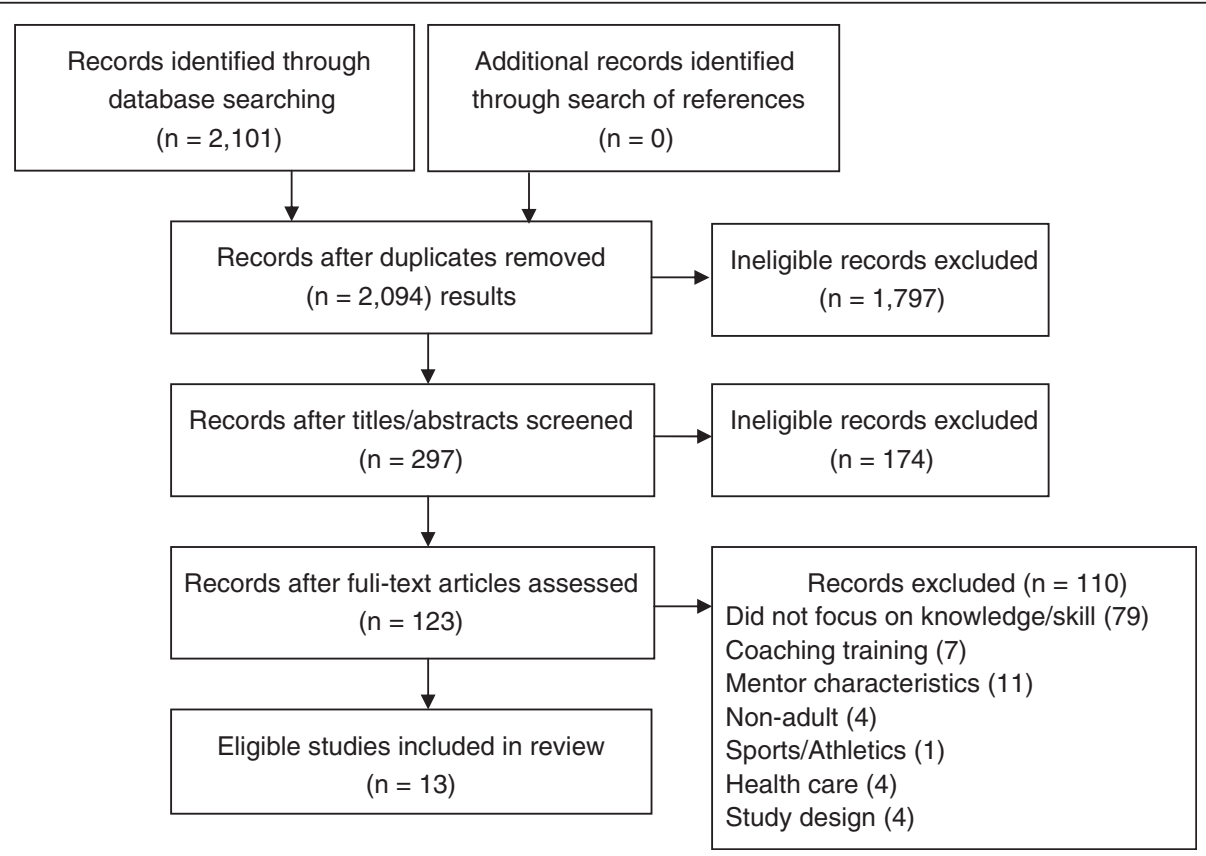

Figure 2 PRISMA diagram of search results. 
Table 2 Summary of mentorship studies identified in business and social science literature

\begin{tabular}{|c|c|c|c|c|c|c|c|c|c|c|}
\hline \multirow[t]{2}{*}{ Study } & \multirow{2}{*}{$\begin{array}{l}\text { Research } \\
\text { design } \\
\text { (Quality) }\end{array}$} & \multirow{2}{*}{$\begin{array}{l}\text { Mentoring goal } \\
\text { (improved or achieved) }\end{array}$} & \multicolumn{8}{|c|}{ Mentoring program design } \\
\hline & & & $\begin{array}{l}\text { Formal } \\
\text { program }\end{array}$ & $\begin{array}{l}\text { Individual or } \\
\text { group }\end{array}$ & $\begin{array}{l}\text { Senior } \\
\text { mentor }\end{array}$ & $\begin{array}{l}\text { Entry } \\
\text { criteria }\end{array}$ & $\begin{array}{l}\text { Mentor } \\
\text { training }\end{array}$ & $\begin{array}{l}\text { Dyad } \\
\text { matching }\end{array}$ & Activities & Duration/Timing \\
\hline Elinger [51] & Survey & \multirow{2}{*}{$\begin{array}{l}\text { Self-reported overall } \\
\text { job performance (yes) }\end{array}$} & \multirow[t]{2}{*}{ No } & \multirow[t]{2}{*}{-} & \multirow[t]{2}{*}{ Yes } & \multirow[t]{2}{*}{ No } & \multirow[t]{2}{*}{ No } & \multirow[t]{2}{*}{ No } & \multirow[t]{2}{*}{-} & \multirow[t]{2}{*}{-} \\
\hline 2011/USA & $(10 / 11)$ & & & & & & & & & \\
\hline Wheeler [59] & Mixed & \multirow{2}{*}{$\begin{array}{l}\text { Company reported sales } \\
\text { performance (yes) }\end{array}$} & \multirow[t]{2}{*}{ No } & \multirow[t]{2}{*}{-} & \multirow[t]{2}{*}{ Yes } & \multirow[t]{2}{*}{ No } & \multirow[t]{2}{*}{ No } & \multirow[t]{2}{*}{ No } & \multirow[t]{2}{*}{-} & \multirow[t]{2}{*}{-} \\
\hline 2011/UK & $(9 / 11)$ & & & & & & & & & \\
\hline Kwan [52] & Survey & \multirow{2}{*}{$\begin{array}{l}\text { Self-reported overall job } \\
\text { performance (yes) }\end{array}$} & \multirow[t]{2}{*}{ Yes } & \multirow[t]{2}{*}{ Individual } & \multirow[t]{2}{*}{ Yes } & \multirow[t]{2}{*}{ No } & \multirow[t]{2}{*}{ No } & \multirow[t]{2}{*}{ No } & \multirow[t]{2}{*}{-} & - \\
\hline 2010/China & $(11 / 11)$ & & & & & & & & & \\
\hline Powell [60] & RCT (low & Teaching skills (yes, & Yes & Both & Yes & No & Yes & No & 2 day workshop, & 7 visits over 15 \\
\hline 2010/USA & risk & $\begin{array}{l}\text { no difference between } \\
\text { remote and on-site) }\end{array}$ & & & & & & & site visits & $\begin{array}{l}\text { weeks, } 90 \text { min } \\
\text { observation, } 30 \text { min } \\
\text { discussion }\end{array}$ \\
\hline Agarwal [53] & Survey & Self-reported overall job & Yes & Both & Yes & Yes & Yes & No & - & - \\
\hline 2009/USA & $(10 / 11)$ & performan & & & & & & & & \\
\hline Bernal [63] & Mixed & Research skills (yes) & Yes & Individual & Yes & - & - & - & Consultation & 2 years \\
\hline 2009/Puerto Rico & $(7 / 11)$ & & & & & & & & ded & \\
\hline Fischer [54] & Mixed & Self-reported overall job & Yes & Individual & Yes & No & Yes & No & Mentor-mentee & 4 hours/month for \\
\hline 2009/USA & $(10 / 11)$ & performance (yes) & & & & & & & discretion & 6 months \\
\hline Levenson [55] & Mixed & Self-reported overall job & Yes & - & Yes & No & No & Yes & - & - \\
\hline 2009/USA & $(8 / 11)$ & & & & & & & & & \\
\hline Yost [61] & Mixed & Teaching skills (yes) & Yes & Individual & Yes & Yes & Yes & No & Workshop, & 3 visits/year, $45 \mathrm{~min}$ \\
\hline 2009/UK & $(10 / 11)$ & & & & & & & & & $\begin{array}{l}\text { observation then } \\
\text { discussion }\end{array}$ \\
\hline Byrne [56] & Survey & Self-reported overall job & Yes & - & Yes & No & No & No & - & - \\
\hline 2008/USA & $(11 / 11)$ & perf & & & & & & & & \\
\hline Stead [57] & Mixed & Self-reported overall job & Yes & Both & Yes & No & Yes & Yes & Workshops, & Every 4 to 6 weeks over \\
\hline 2005/UK & $(8 / 11)$ & performance & & & & & & & meetings & 9 months \\
\hline Browne-Ferrigno & Mixed & Teaching skills (yes) & Yes & Individual & No (peer) & - & - & - & Meetings & 4 hours once per \\
\hline [62] 2004/USA & $(7 / 11)$ & & & & & & & & & \\
\hline Wales [58] & Mixed & Self-reported overall job & Yes & Individual & Yes & No & Yes & Yes & Meetings & 1 hour every 2 weeks \\
\hline 2002/UK & $(8 / 11)$ & & & & & & & & & \\
\hline
\end{tabular}


research skills [63]. All studies reported achieving desired goals, or improving performance or skills except for two in which mentoring focused on job performance [55] and teaching skills [62].

\section{Mentoring design}

Most studies examined formal, organized mentoring programs in which mentees were matched with mentors and/or specific mentoring activities were offered. Two studies examined informal mentoring programs in which the mentor-mentee relationship occurred spontaneously $[51,59]$. In six studies mentoring involved a single mentor and mentee [52,54,58,61-63], and in three studies mentoring combined individual and group activities $[53,57,60]$, for example, participation in a two-day workshop followed by expert coaching [60]. Mentoring was hierarchical in most studies, meaning that the mentor was senior to the mentee or an expert. One study involved peer mentoring [62]. Two mentoring programs described eligibility criteria for mentees, for example, pre-requisite orientation prior to participation [53,61]. In six studies mentors were trained [53,54,57,58,60,61]. Mentoring programs matched mentors and mentees in three studies $[55,57,58]$. Of the seven studies that described mentoring program activities, three involved a training workshop followed by mentoring meetings or site visits [57,60,61] and four involved mentoring only $[54,58,62,63]$. In one of the mentoring-only studies, the frequency of meetings was left to the discretion of the mentor and mentee [63]. The duration of mentoring ranged from four months to two years. The frequency of mentoring meetings or site visits during specified periods was variable.

\section{Mentoring barriers}

Two studies assessed challenges associated with mentoring $[51,57]$. Mentoring programs were resource intensive, requiring organizational support for sustainability and infrastructure for recruitment and matching. Feeling neglected by their mentor and mentor trustworthiness were also a concern for mentees. Others found that the goals were not clearly laid out by the mentorship program.

\section{Summary of eligible study findings}

Data were examined to identify whether mentoring design features may be associated with impact. This also served to identify gaps in research. Of 13 studies, 12 reported achieving or improving desired knowledge, skills, or performance. Mentoring program design varied across these studies, as did the type of activities offered, and the duration and timing of mentoring in studies that reported these details. Therefore, potential associations were not identified. In the only study that did not achieve desired outcomes [55], the mentoring program design did not differ from that of studies in which mentoring had a positive impact. Another way to interpret these findings is that successful formal mentoring programs that are meant to enhance knowledge, skills, or performance may include individual and/or group mentoring offered by a senior or expert mentor. Mentor training may be required though entry criteria and dyad matching may not be necessary. Mentors and mentees should meet periodically over a given period of time from six months to one year, though optimal frequency is not clear. A preliminary workshop prior to mentoring can be used to transmit knowledge that is then reinforced by mentoring. However, it is notable that even informal mentoring with little infrastructure or processes achieved beneficial outcomes [51,59].

Data about design features and study findings were compared with components of the conceptual framework (Figure 1) to further identify gaps in research. Stages of mentoring were not addressed in eligible studies. Screening, matching, and training were described in some studies, though mentor training was most frequently addressed. Feedback and ongoing support were not addressed in eligible studies, however, preliminary training workshops were sometimes used to introduce concepts that were later reinforced by mentoring. Frequency, intensity, and duration were variable across studies in which mentoring had a positive impact. Most eligible studies involved formal mentoring, though two studies of informal mentoring also achieved positive results. Individual, and combined individual and group mentoring both resulted in beneficial outcomes. One trial found that mentoring delivered in person or remotely achieved similarly positive results. No studies involved or examined the roles of multiple mentors, ideal mentor characteristics, or outcomes experienced by mentors. This study focused on transfer of expertise so this was the only mentor role examined, and impact was limited to measures reflecting knowledge, skill and behaviour, most often by self-report. Barriers already included in the conceptual framework that were confirmed by eligible studies included clarity of goals. Additional barriers identified (italicized in Figure 1) included the need for resources and infrastructure, and issues related to the mentor-mentee relationship including feeling neglected by the mentor, and lack of confidence or trust in mentor expertise.

\section{Gaps in research}

Recommendations for ongoing research were identified in two ways. First, data were examined to identify details that were often not reported by eligible studies. Two studies did not report information about matching of mentors and mentees, mentor training, or requirements of participation $[62,63]$. Several studies provided no details about mentoring activities, and duration and timing of mentoring [51-53,55,56,59]. Ongoing research that evaluates mentorship should more consistently report such details, 
and studies that develop, implement, and evaluate mentoring as an intervention should consider these design features when developing the mentoring program. Components of the conceptual framework not examined in eligible studies but that may be relevant to KT mentorship and warrant ongoing research includes stages of mentoring, mentor characteristics, roles and outcomes, and feedback and ongoing support. A concept revealed in eligible studies not already part of the conceptual framework that also warrants further research is how to blend group or training activities with mentoring. Neither the conceptual framework nor the eligible studies described the content of mentoring interactions. These unique concepts were added to the conceptual framework (Figure 1).

\section{Discussion}

The purpose of this research was to identify essential components of mentoring used in management and social science applications that could form the basis of KT mentorship programs. Notably, all but one of the 13 eligible studies achieved desired outcomes or improvements in knowledge, skills, or associated behavior. These mentoring programs combined preliminary workshopbased training with individual mentoring; mentors received training and were either senior employees or external experts; and mentoring was offered for at least an hour periodically over a minimum of six months. One trial with positive results found that remote and in-person mentoring had similar impact. Some, but not all programs offered screening based on criteria or prerequisites, and mentor-mentee matching.

Interpretation and application of these findings are limited by several factors. We may not have identified all relevant studies despite employing a comprehensive search strategy and robust review methods. To enhance relevance of the findings for developing $\mathrm{KT}$ capacity we restricted the review to studies that focused on mentoring for job-specific knowledge or skills. Many of the search results focused on job satisfaction, organizational commitment and measures of career success such as promotion and salary. Such studies were not eligible so few studies were reviewed overall. While the quality of most studies was relatively high, the designs of these studies are more prone to bias in establishing a causal relationship between mentoring and the outcome of interest. Mentoring programs varied considerably in goals, design (frequency, intensity, duration) and measures of impact so pooling of data was not possible, nor would it be an option for future research, further limiting the inferences that can be drawn from this review. However, a strength of this study was use of a conceptual framework by which to analyze data, and identify gaps in knowledge and recommendations for future research, which is a key purpose for a scoping review.
KT training programs mentioned earlier [20,21] already include mentoring but published reports lacked details about this component, partially spurring this scoping review. Unfortunately, eligible studies lacked details about mentorship design and content. Ongoing research that evaluates mentorship should more consistently report such details, and studies that develop, implement, and evaluate mentoring as an intervention should consider these design features when developing the mentoring program. This has been advocated by others [64]. As a behavioural intervention, those interested in evaluating mentorship could draw upon established reporting guidelines combined with elements of the conceptual framework described here to more comprehensively address and then report design and content details $[65,66]$.

Though only two of the eligible studies assessed barriers, several were identified, including the need for considerable infrastructure and resources to support activities such as recruitment, matching, and preliminary training events; lack of clarity in mentoring goals; and limited confidence in, and satisfaction with mentors and their availability. These barriers have also been identified by others, though in reference to academic mentoring $[34,67]$. Further research is needed to investigate optimal means by which to prevent or mitigate these issues. Such research might examine optimal training for KT mentors, and how to engage in remote mentoring as this may enhance access to mentors.

Several issues included in the conceptual framework were not addressed by eligible studies. This included stages of mentoring; and feedback and ongoing support. Ongoing studies that evaluate mentorship for developing KT capacity should explore whether and how complementary activities or mentoring content should be tailored according to baseline knowledge or skill, individual KT needs, and maturity of the mentoring relationship that reflects stages of mentoring. Such studies could also examine whether periodic interaction or other type of support may be needed following the formal period of mentorship to reinforce learning. No eligible studies examined mentor characteristics or outcomes. Given that the mentor characteristics may strongly influence the formation, function, and success of mentoring [34], further research should investigate the ideal characteristics of KT mentors. Eligible studies did not address the need for multiple mentors with differing roles. It has been recognized that those in influential roles may promote development or improvement in a variety of ways that include directing, teaching, championing or facilitating [68]. Roles may further differ based on the nature of the relationship. For example, coaching involves work-situated, specific and structured training over a finite period of time and is often delivered by a supervisor [69]. In contrast, mentoring is meant to address one or more personal, social, 
and professional needs through exchange of knowledge and sharing of experiences that may evolve over an extended period of time and can assume a variety of formats. The mentoring model may require one or more mentors with differing experience or over time to address multiple needs. Therefore further research could explore whether coaching, mentoring or both can best contribute to the development of KT capacity.

\section{Conclusion}

Key components of mentoring programs that may form the basis of KT mentorship include combining preliminary workshop-based training with individual mentoring provided either in person or remotely; training of mentors; and periodic mentoring for at least an hour over a minimum period of six months. Further research is needed to address identified gaps includes developing and implementing, or evaluating existing KT mentorship programs based on the factors identified here, and examining whether and how $\mathrm{KT}$ mentorship develops KT capacity.

\section{Competing interests}

The authors declare that they have no competing interests.

\section{Authors' contributions}

ARG conceived the study, acquired funding, coordinated all aspects of its conduct, and prepared this manuscript. All authors contributed to study planning, and data collection and interpretation, and reviewed and approved the final version of this manuscript.

\section{Acknowledgements}

This study was funded by the Canadian Institutes of Health Research which took no part in its conception, design, conduct, interpretation, or preparation of this manuscript.

\section{Author details}

${ }^{1}$ University Health Network, Toronto, Canada. ${ }^{2}$ University of Toronto, Toronto, Canada. ${ }^{3}$ St. Michael's Hospital, Toronto, Canada. ${ }^{4}$ Sunnybrook Health Sciences Centre, Toronto, Canada.

Received: 20 February 2014 Accepted: 12 July 2014

Published online: 25 September 2014

\section{References}

1. McGlynn EA, Asch SM, Adams J, Keesey J, Hicks J, De Cristofaro A, Kerr EA: The quality of health care delivered to adults in the United States. N Engl J Med 2003, 348(26):2635-2645.

2. Graham ID, Logan J, Harrison MB, Straus SE, Tetroe J, Caswell W, Robinson N: Lost in knowledge translation: time for a map? J Contin Educ Health Prof 2006, 26(1):13-24.

3. Kothari A, Wathen $\mathrm{CN}$ : A critical second look at integrated knowledge translation. Health Policy 2013, 109(2):187-191

4. Estabrooks CA, Thompson DS, Lovely JJ, Hofmeyer A: A guide to knowledge translation theory. J Contin Educ Health Prof 2006, 26:25-36.

5. Sheldon TA, Cullum N, Dawson D, Lankshear A, Lowson K, Watt I, West P Wright $D$, Wright J: What's the evidence that NICE guidance has been implemented? Results from a national evaluation using time series analysis, audit of patients' notes, and interviews. BMJ 2004, 329(7473):999.

6. Koshy A, Buckingham JM, Zhang Y, Craft P, Dahlstrom JE, Tait N, and members of the ACT and SE NSW Breast Cancer Treatment Group: Surgical management of invasive breast cancer: a 5-year prospective study of treatment in the Australian Capital Territory and South-Eastern New South Wales. ANZ J Surg 2005, 75(9):757-761.
7. Lavis JN, Robertson D, Woodside JM, McLeod CB, Abelson J: How can research organizations more effectively transfer research knowledge to decision makers? Milbank Q 2003, 81(2):221-248.

8. Newton MS, Estabrooks CA, Norton P, Birdsell JM, Adewale AJ, Thornley R: Health researchers in Alberta: an exploratory comparison of defining characteristics and knowledge translation activities. Implement Sci 2007, 2:1.

9. Segrott J, Mclvor M, Green B: Challenges and strategies in developing nursing research capacity: a review of the literature. Int J Nurs Stud 2006, 43(5):637-651.

10. Cooke J, Nancarrow S, Dyas J, Williams M: An evaluation of the Designated Research Team Approach to building research capacity in primary care. BMC Fam Pract 2008, 9(1):37.

11. Cooke J: A framework to evaluate research capacity building in health care. BMC Fam Pract 2005, 6:44

12. Haas M: Health services research in Australia: an investigation of its current status. J Health Serv Res Policy 2004, 9(Suppl 2):3-9.

13. Arnold LK, Alomran H, Anantharaman V, Halpern P, Hauswald M, Malmquist $P$, Molyneux E, Rajapakse B, Ranney M, Razzak J: Knowledge translation in international emergency medical care. Acad Emerg Med 2004, 14(11):1047-1051.

14. Kilian BJ, Binder LS, Marsden J: The emergency physician and knowledge transfer: continuing medical education, continuing professional development, and self-improvement. Acad Emerg Med 2004, 14(11):1003-1007.

15. Dayan PS, Osmond M, Kuppermann N, Lang E, Klassen T, Johnson D, Strauss S, Hess E, Schneider S, Afilalo M, Pusic M: Development of the capacity necessary to perform and promote knowledge translation research in emergency medicine. Acad Emerg Med 2004, 14(11):978-983.

16. Huckson S, Davies J: Closing evidence to practice gaps in emergency care: The Australian experience. Acad Emerg Med 2004, 14(11):1058-1063.

17. Tetroe JM, Graham ID, Foy R, Robinson N, Eccles MP, Wensing M, Durieux P, Légaré F, Nielson CP, Adily A, Ward JE, Porter C, Shea B, Grimshaw JM: Health research funding agencies' support and promotion of knowledge translation: an international study. Milbank Q 2008, 86(1):125-155.

18. Gagliardi AR, Fraser N, Wright FC, Lemieux-Charles L, Davis D: Fostering knowledge exchange between researchers and decision-makers: exploring the effectiveness of a mixed-methods approach. Health Policy 2008, 86(1):53-63.

19. Meissner HI, Glasgow RE, Vinson CA, Chambers D, Brownson RC, Green LW, Ammerman AS, Weiner BJ, Mittman B: The U.S. training institute for dissemination and implementation research in health. Implement SCi 2013, 8:12

20. Proctor EK, Landsverk J, Baumann AA, Mittman BS, Aarons GA, Brownson RC, Glisson C, Chambers D: The implementation research institute: training mental health implementation researchers in the United States. Implement SCi 2013, 8:105.

21. Straus SE, Brouwers M, Johnson D, Lavis JN, Legare F, Majumdar SR, McKibbon KA, Sales AE, Stacey D, Klein G, Grimshaw J: Core competencies in the science and practice of knowledge translation: description of a Canadian strategic training initiative. Implement Sci 2011, 6:127.

22. Karcher MJ, Kuperminc GP, Portwood SG, Sipe CL, Taylor AS: Mentoring programs: A framework to inform program development, research, and evaluation. J Community Psychol 2006, 34(6):709-725.

23. Allen TD, Eby LT, Lentz E: The relationship between formal mentoring program characteristics and perceived program effectiveness. Personnel Psychol 2006, 59:125-153.

24. Kram KE: Phases of the mentor relationship. Acad Manage J 1983, 26:608-625.

25. Fagenson-Eland EA, Marks MA, Amendola KL: Perceptions of mentoring relationships. J Voc Behav 1997, 51:29-42.

26. Allen TD, Eby LT, Poteet ML, Lentz E, Lima L: Career benefits associated with mentoring for protégés: A meta-analysis. J Appl Psychol 2004, 89:127-136

27. Noe RA: An investigation of the determinants of successful assigned mentoring relationships. Personnel Psychol 1988, 41:457-479.

28. Chao GT, Gardner PD: Formal and informal mentorships: A comparison on mentoring functions and contrast with non-mentored counterparts. Personnel Psychol 1992, 45:619-636.

29. Allen TD, Poteet ML, Burroughs SM: The mentor's perspective: $A$ qualitative inquiry and future research agenda. J Voc Behav 1997 51:70-89. 
30. Eby LT: Alternative forms of mentoring in changing organizational environments: A conceptual extension of the mentoring literature. J Voc Behav 1997, 51:125-144.

31. McKenna AM, Straus SE: Charting a professional course: a review of mentorship in medicine. J Am Coll Radiol 2011, 8:109-112.

32. Straus SE, Sackett DL: Mentoring: why every clinician-trialist needs to get mentored. Clin Trials 2011, 8:765-767.

33. Sambunjak D, Straus SE, Marusic A: Mentoring in academic medicine: a systematic review. J Am Med Assoc 2006, 296:1103-1115.

34. Straus SE, Chatur F, Taylor M: Issues in the mentor-mentee relationship in academic medicine: a qualitative study. Acad Med 2009, 84:135-139.

35. Dyer $L$ : The continuing need for mentors in nursing. J Nurs Staff Dev 2008, 24(2):86-90

36. Kim KH: Clinical competence among senior nursing students after their preceptorship experiences. J Prof Nurs 2007, 23(6):369-375.

37. Lillibridge J: Using clinical nurses as preceptors to teach leadership and management to senior nursing students. Nurse Educ Pract 2007, 7(1):44-52.

38. Prestholdt C: Modern mentoring: Strategies for developing contemporary nursing leadership. Nurs Admin Q 1990, 15:20-27.

39. Billay D, Myrick F: Preceptorship: an integrative review of the literature. Nurs Educ Pract 2008, 8(4):258-266.

40. Udlis KA: Preceptorship in undergraduate nursing education: an integrative review. J Nurs Educ 2008, 47(1):20-29.

41. Stewart BM, Krueger LE: An evolutionary concept analysis of mentoring in nursing. J Prof Nursing 1996, 12:311-321.

42. Hyrkas K, Shoemaker M: Changes in the preceptor role: revisiting preceptors' perceptions of benefits, rewards, support and commitment to the role. J Adv Nurs 2007, 60(5):513-523.

43. Zilembo M, Monterosso L: Nursing students perceptions of desirable leadership qualities in nursing preceptors. Contemp Nurs 2008, 27(2):194-206.

44. Andrews $M$, Wallis $M$ : Mentorship in nursing: $A$ review of the literature J Adv Nurs 1999, 29:201-207.

45. Byrne MW, Keefe MR: Building research competence in nursing through mentoring. J Nurs Scholar 2002, 34(4):391-396.

46. Blauvelt MJ, Spath ML: Passing the torch: a faculty mentoring program at one school of nursing. Nurs Educ Perspect 2008, 29(1):29-33.

47. Arksey H, O'Malley L: Scoping studies: Towards a methodological framework. Int J Soc Res Methodol 2005, 8:19-32.

48. Moher D, Liberati A, Tetzlaff J, Altman DG, The PRISMA Group: Preferred Reporting Items for Systematic Reviews and Meta-Analyses: The PRISMA Statement. BMJ 2009, 339:b2535.

49. Higgins JPT, Altman DG, Gotzsche PC, Juni P, Moher D, Oxman AD, Savovic J, Schulz KF, Weeks L, Sterne JA, Cochrane Bias Methods Group, Cochrane Statistical Methods Group: The Cochrane Collaboration's tool for assessing risk of bias in randomized trials. BMJ 2011, 343:d5928.

50. Downs SH, Black N: The feasibility of creating a checklist for the assessment of the methodological quality both of randomized and non-randomized studies of health care interventions. J Epidemiol Community Health 1998, 52:377-384.

51. Ellinger $A D$, Ellinger $A E$, Bachrach $D G$, Wang $Y$, Elmadağ Baş $A B$ : Organizational investments in social capital, managerial coaching, and employee work-related performance. Manag Learn 2011, 42:67-85.

52. Kwan HK, Mao Y, Zhang H: The impact of role modeling on protégés' personal learning and work-to-family enrichment. J Voc Behav 2010, 77:313-322

53. Agarwal R, Angst CM, Magni M: The performance effects of coaching: a multilevel analysis using heirarchical linear modeling. Int I Human Res Manage 2009, 20:2110-2134.

54. Fischer RL, Beimers D: Put me in, Coach": A pilot evaluation of executive coaching in the nonprofit sector. Nonprof Manag Leader 2009, 19:507-522.

55. Levenson A: Measuring and maximizing the business impact of executive coaching. Consult Psychol J Pract Res 2009, 61:103-121.

56. Byrne ZS, Dik BJ, Chiaburu DS: Alternatives to traditional mentoring in fostering career success. J Voc Behav 2008, 72:429-442.

57. Stead V: Mentoring: a model for leadership development? Int J Train Dev 2005, 9:170-184.

58. Wales S: Why coaching? J Change Manage 2002, 3:275-282.

59. Wheeler L: How does the adoption of coaching behaviours by line managers contribute to the achievement of organisational goals? Int J Evid Based Coach Mentor 2011, 9:1-15.
60. Powell DR, Diamond KE, Burchinal MR, Koehler MJ: Effects of an early literacy professional development intervention on head start teachers and children. J Educ Psychol 2010, 102:299-311.

61. Yost DS, Vogel R, Liang LL: Embedded teacher leadership: support for a site-based model of professional development. Int J Leader Educ 2009, 12:409-433.

62. Browne-Ferrigno T: Leadership mentoring in clinical practice: role socialization, professional develoment, and capacity building. Educ Adm Q 2004, 40:468-494.

63. Bernal G, Ortiz-Torres B: Barriers to Research and Capacity Building at Hispanic-Serving Institutions: The Case of HIV/AIDS Research at the University of Puerto Rico. Am J Public Health 2009, 99:560-s65.

64. Michie S, Fixsen D, Grimshaw JM, Eccles MP: Specifying and reporting complex behaviour change interventions: the need for a scientific method. Implement Sci 2009, 4:40.

65. Proctor EK, Powell BJ, McMillen CJ: Implementation strategies: recommendations for specifying and reporting. Implement Sci 2013, 8:139.

66. Albrecht L, Archibald M, Arseneau D, Scott SD: Development of a checklist to assess the quality of reporting of knowledge translation interventions using the Workgroup for Intervention Development and Evaluation Research (WIDER) recommendations. Implement Sci 2013, 8:52.

67. Straus SE, Johnson MO, Marquez C, Feldman MD: Characteristics of successful and failed mentoring relationships. Acad Med 2013, 88:82-89.

68. Thompson GN, Estabrooks CA, Degner LF: Clarifying the concepts in knowledge transfer: a literature review. J Adv Nurs 2006, 53:691-701.

69. Thompson R, Wolf D, Sabatine JM: Mentoring and coaching: A model guiding professional nurses to executive success. J Nurs Admin 2012, 42:536-541.

doi:10.1186/s13012-014-0122-z

Cite this article as: Gagliardi et al:: Exploring mentorship as a strategy to build capacity for knowledge translation research and practice: a scoping systematic review. Implementation Science 2014 13:122.

\section{Submit your next manuscript to BioMed Central and take full advantage of:}

- Convenient online submission

- Thorough peer review

- No space constraints or color figure charges

- Immediate publication on acceptance

- Inclusion in PubMed, CAS, Scopus and Google Scholar

- Research which is freely available for redistribution 